\title{
Cervical Myolipoma with Pregnancy: Report of a Case and Brief Review of Literature
}

\author{
Kaushal Manila, Maru Laxmi, Patidar Ranjana \\ Department of Obstetrics \& Gynecology, MGM Medical College, Indore (M.P.) India
}

\begin{abstract}
:
Cervical myolipoma is extremely rare. We report a case of cervical myolipoma in a 26-year-old pregnant female who was admitted with complaints of term pregnancy with mass protruding out of introitus. On examination mass was arising from cervix. With the clinical suspicion of fibroid polyp, an excisional biopsy was done. A histopathological examination showed bundles and sheaths of smooth muscle interspersed with islands of mature adipose tissue without nuclear atypia.
\end{abstract}

Key words: myolipoma, pregnancy.

\section{Introduction}

Myolipoma of the uterus is an exceedingly rare entity. Only a few cases of lipoma of uterus have been reported in the last few decades. It is a benign soft tissue tumor that is composed of smooth muscle cells and adipocytes $^{1}$. It may occur in many anatomic sites throughout the body including, retro peritoneum ${ }^{2}$, abdominal cavity, uterus and adnexae, pericardium, and breast. They usually develop in postmenopausal women $^{3,4}$. A case of isolated myolipoma uterus arising from cervix in young pregnant women which was diagnosed postoperatively by histopathological examination is presented.

\section{Case}

A 26 year old Indian woman, Gravida2 Para1 at 37 weeks of gestation was admitted in labour ward as an emergency case with labour pain and a huge mass lying outside the vagina. She had normal vaginal delivery two years back at home. She is illiterate, belongs to low socioeconomic group and had not received antenatal care throughout the pregnancy. She was attempted to deliver by traditional birth attendant at home. On bearing down mass which was lying in vagina prolapsed outside the introitus and was then brought to hospital with above complaints. On admission tachycardia was present; BP was normal and was afebrile. Per abdomen uterus was 32 weeks size, longitudinal lie and cephalic presentation. The fetal heart rate baseline was $100 \mathrm{bpm}$ with moderate variability and no decelerations. The uterine contraction pattern was weak and irregular with 1-2 contractions in 10 minutes. On perineal examination a solid mass of 30 x $20 \mathrm{~cm}$ size lying outside the introitus was seen. (Fig 1) On per vaginal examination mass was arising from the cervix. At cervical examination, there was $5 \mathrm{~cm}$ dilatation, vertex at -3 station and liquor was thick meconium stained. Emergency caesarean section was done under spinal anesthesia, indication was fetal distress. The birth weight was $3190 \mathrm{~g}$ and Apgar scores of 6, 8, and 9, at 1,5 , and 10 minutes were assigned. Placental pathology showed no abnormality. Examination under anesthesia was done to confirm the origin of mass. The mass was arising from anterior lip of cervix and attached to it by a broad stalk. A provisional diagnosis of fibroid polyp was made and resection done. The resected tumor was well encapsulated, yellow-white with area of necrosis and $30 \times 15 \times 8 \mathrm{~cm}$ in size. Histologically, it consisted of bundles and sheaths of smooth muscle interspersed with islands of mature adipose tissue (Fig 2). Neither nuclear atypia nor mitosis was observed in either component.

A diagnosis of myolipoma was made. Postoperative period was uneventful.

\section{Comment}

Myolipomas of the uterus are extremely rare. Clinical symptoms and physical signs are similar to those found in leiomyomas. These create preoperative diagnostic confusion, its recognition is important for the avoidance of erroneous diagnoses. They are usually

\section{Correspondence}

Dr Manila Kaushal, MS, DNB, MNAMS, MICOG

Asst Prof, Dept of Ob Gyn, MGM Medical College, Indore (M.P.) India

403, Utsav Avenue, 12/5 Usha Ganj, Jaora compound Indore (M.P.) - 452001

Phone No9424811188E-mail: dr_manila@yahoo.co.in 


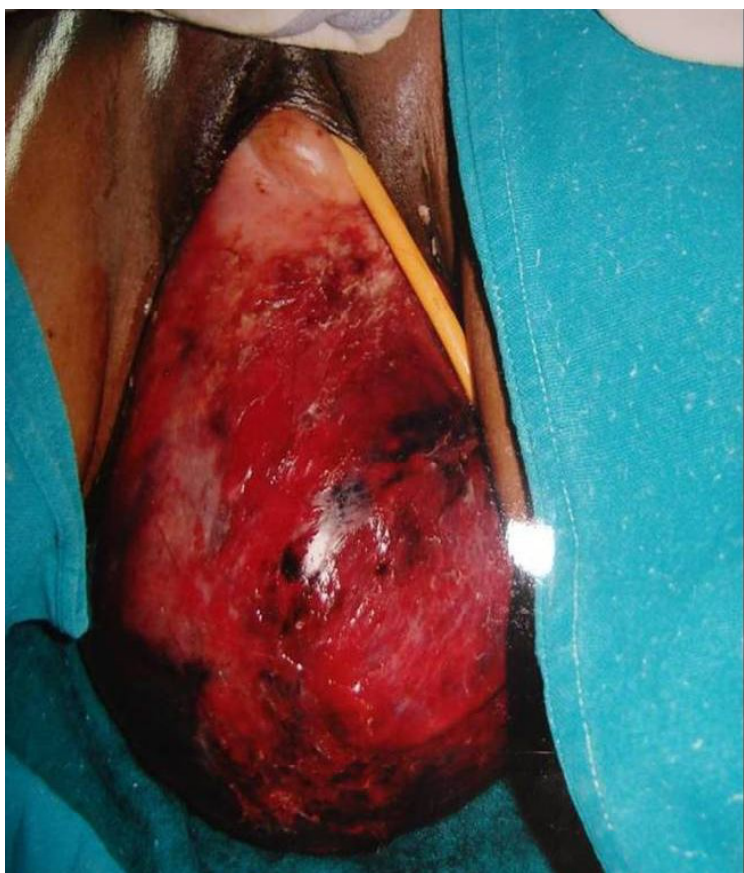

Fig1. Prolapsed cervical myolipoma

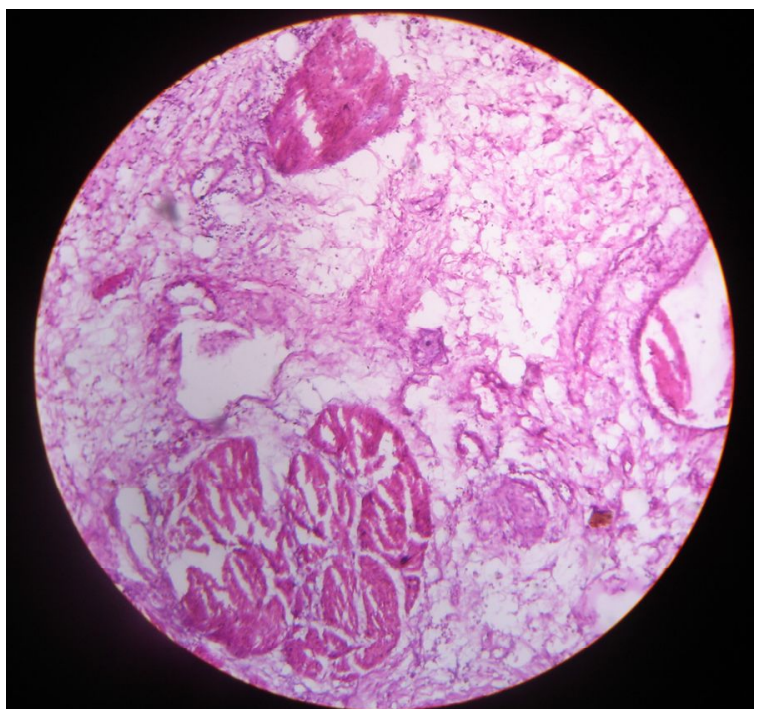

Fig 2. HPE showing smooth muscle with fat cells.

large at initial presentation with a greatest diameter of more than $10 \mathrm{~cm}^{1}$. Complete surgical resection of a myolipoma is considered to be curative, with no known reports or local recurrence, metastatic disease or malignant transformation ${ }^{1}$.

Myolipoma of the uterus seems to have an uneventful clinical course and can now be confidently regarded as benign ${ }^{3}$.

Histogensis is also not very clear. Because fat tissue is not native to the myometrium, various theories have been proposed for the histogenesis of these tumors. A histopathology study suggested that fatty metamorphosis of smooth muscle cells of a leiomyoma is the most likely etiologic factor in the formation of adipose tissue, rather than fatty degeneration.
Lipomatous uterine tumors are typically found in postmenopausal women and are associated with leiomyomas ${ }^{3}$. In present case, unusually, it was found in young pregnant women.

They usually occur in corpus, predominantly intramurally; however, they may be subserosal. The masses may be endophytic or exophytic, with respect to the uterus. Occurrence in cervix is a rare presentation.

The usefulness of the various imaging methods has been discussed in correctly diagnosing this entity and avoiding unnecessary surgery in the asymptomatic patient ${ }^{5}$. Pelvic lipomatous tumors can be diagnosed with ultrasound and CTscan, although MRI may yield more valuable data for differential diagnosis ${ }^{6}$.

Coumbaras et al presented case of a pure lipoma with pathologic correlation in which a preoperative diagnosis was made by $\mathrm{MRI}^{7}$. CT and MRI are useful in differentiating uterine lipoleiomyomas from more common fat-containing pelvic masses like ovarian teratomas, which have an altogether different management and prognosis.

A case of cervical myolipoma with unusual presentation is presented. Myolipoma is a rare soft tissue tumor that is frequently large and deeply located, but clinically benign. This case was unusual as the tumor was found in young pregnant women which herniated through the vagina outside the intiroitus. Correct recognition of the tumor was essential for accurate surgical planning.

\section{References}

1 Murphey MD, Carroll JF, Flemming DJ, Pope TL, Gannon FH, Kransdorf MJ. From the archives of the AFIP: benign musculoskeletal lipomatous lesions. Radiographics 2004; 24:1433-1466.

2. Takahashi Y, Imamura T, Irie H, et al. Myolipoma of the retroperitoneum. Pathol Int 2004; 54:460-463.

3 Fujimoto Y, Kasai K, Furuya M, Honda N, Tojo R, Saito $\mathrm{S}$ et al. Pure uterine lipoma.J Obstet Gynaecol Res. 2006 Oct; 32(5):520-3.

4 Al-Maghrabi JA, Sait KH, Lingawi SS. Uterine lipoma. Saudi Med J. 2004 Oct; 25(10):1492-4.

5 Lau LU, Thoeni RF. Case report. Uterine lipoma:advantage of MRI over ultrasound $\mathrm{Br} \mathrm{J}$ Radiol. 2005 Jan; 78(925):72-4.

6 Erdem G, Celik O, Karakas HM, Alkan A, Hascalik SMagn Pure uterine lipoma.Reson Imaging. 2007 Oct; 25(8):1232-6.

7 Coumbaras M, Validire P, Strauss C, Herry M, Dahan H, Palau R. Uterine lipoma: MRI features with pathologic correlation. Abdom Imaging. 2005 Mar-Apr; 30(2):239-41. 